\title{
Acquired Pulmonary Stenosis
}

\author{
JOHN SEYMOUR, RICHARD EMANUEL, AND NORMAN PATTINSON* \\ From the Cardiac and X-ray Departments, The Middlesex Hospital, London W.1
}

Acquired pulmonary stenosis refers to narrowing of the right ventricular outflow tract or main pulmonary artery which has developed after birth. It may arise from external pressure or from an intrinsic pathological process, and is generally regarded as a rare condition because few cases have been reported. Our experience, however, suggests that it is probably not as rare as previously believed and can frequently be diagnosed during life.

In this paper we review the clinical and radiological features of 13 patients with acquired pulmonary stenosis. Nine were investigated during the past 12 years at the Middlesex Hospital, 3 were seen by Dr. Celia Oakley at the Hammersmith Hospital, and 1 by Mr. W. P. Cleland at King's College Hospital.

Acquired pulmonary stenosis produced by aneurysms of the sinuses of Valsalva and aneurysms of the interventricular septum as well as the malignant carcinoid syndrome have not been discussed, since they are considered to be beyond the scope of this paper. Inflammatory lesions referred to by Babcock, Judge, and Bookstein (1962) and listed in Table I as possible causes are also omitted from our discussion because we have not had the opportunity of investigating such a case.

\section{ClINICAL, ELECTROCARDIOGRAPHIC, AND HAEMODYNAMIC FINDINGS}

The symptoms, physical signs, electrocardiographic, and haemodynamic findings in the 13 cases reviewed are summarized in Table II. The commonest symptoms at the time of diagnosis were chest pain (9 patients) and cough ( 7 patients). Only 2 patients were in frank congestive cardiac failure with peripheral oedema. Six patients had previously passed a full medical examination.

All the patients were in sinus rhythm and all had a systolic murmur at the left sternal edge; in 5

Received January 31, 1968.

$\star$ Requests for reprints should be addressed to this author. patients this was associated with a thrill. There was abnormal pulsation over the right ventricle in 8 and an increase of the mean jugular venous pressure in 6. Six patients had immediate diastolic murmurs. Observations on the pulmonary second sound were incomplete but it was accentuated in one patient.

The electrocardiogram showed right ventricular enlargement in 2 patients, a left bundle-branch block in one, and was normal in the remainder.

Pressure measurements were made in 7 patientsin 2 of these the pulmonary artery was not entered, but the systolic pressure in the right ventricle was

\section{TABLE I}

PREVIOUSLY REPORTED CAUSES OF PULMONARY STENOSIS, AND AETIOLOGY IN THE PRESENT 13 CASES

\begin{tabular}{|c|c|c|}
\hline & $\begin{array}{l}\text { No. of } \\
\text { cases }\end{array}$ & $\begin{array}{l}\text { Case } \\
\text { No. }\end{array}$ \\
\hline 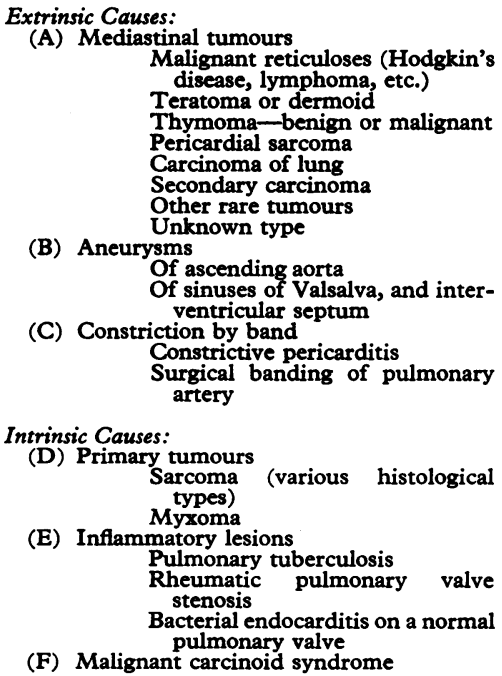 & $\begin{array}{c}1 \\
4 \\
1 \\
1 \\
1 \\
1 \\
1 \\
1 \\
- \\
1 \\
-\end{array}$ & $\begin{array}{r}1 \\
2-5 \\
6 \\
8 \\
9 \\
10 \\
7 \\
11 \\
- \\
12 \\
-\end{array}$ \\
\hline
\end{tabular}


TABLE II

SYMPTOMS AND SIGNS IN 13 PATIENTS

\begin{tabular}{|c|c|c|c|c|c|c|c|c|c|c|c|c|c|c|}
\hline Case No. & 1 & 2 & 3 & 4 & 5 & 6 & 7 & 8 & 9 & 10 & 11 & 12 & 13 & Total \\
\hline $\begin{array}{l}\text { Symptoms } \\
\text { Previously normal examination } \\
\text { Chest pain } \\
\text { Dyspnoea } \\
\text { Cough } \\
\text { Haemoptysis } \\
\text { Fever } \\
\text { Palpitation } \\
\text { Oedema }\end{array}$ & $\begin{array}{l}+ \\
+ \\
+\end{array}$ & $\stackrel{+}{+}$ & $\begin{array}{l}+ \\
+ \\
+ \\
+\end{array}$ & + & + & + & $\begin{array}{l}+ \\
+\end{array}$ & $\begin{array}{l}+ \\
+ \\
+ \\
+ \\
+\end{array}$ & + & $\begin{array}{l}+ \\
+ \\
+\end{array}$ & $\begin{array}{l}+ \\
+ \\
+\end{array}$ & + & + & $\begin{array}{l}6 \\
9 \\
7 \\
3 \\
2 \\
2 \\
1 \\
1 \\
2\end{array}$ \\
\hline $\begin{array}{l}\text { Signs } \\
\text { Sinus rhythm } \\
\text { Raised jugular venous pressure } \\
\text { Right ventricular hypertrophy } \\
\text { Systolic murmur } \\
\text { Systolic thrill } \\
\text { Diastolic murmur } \\
\text { P2 quality } \\
\text { P2 movement } \\
\text { Electrocardiogram } \\
\text { Peak systolic pressure gradient } \\
\text { (mm. Hg) }\end{array}$ & $\begin{array}{r}+ \\
+ \\
+ \\
+ \\
+ \\
\stackrel{+}{\mathbf{R}} \\
\mathbf{R V}+ \\
?\end{array}$ & $\begin{array}{c}\mathbf{N} \\
\mathbf{N} \\
\mathbf{N} \\
?\end{array}$ & $\begin{array}{l}+ \\
+ \\
+ \\
+ \\
? \\
? \\
\stackrel{3}{?} \\
?\end{array}$ & $\begin{array}{c}+ \\
+ \\
+ \\
\\
\mathbf{N} \\
\mathbf{N} \\
\mathbf{5 0 / 0 ^ { \star }}\end{array}$ & $\begin{array}{l}\mathbf{N} \\
\mathbf{N} \\
\mathbf{N} \\
35\end{array}$ & $\begin{array}{l}+ \\
+ \\
+ \\
+ \\
? \\
? \\
\stackrel{?}{+} \\
10\end{array}$ & $\begin{array}{l}+ \\
\text { ? } \\
? \\
? \\
? \\
?\end{array}$ & $\begin{array}{l}+ \\
+ \\
+ \\
+ \\
+\end{array}$ & \begin{tabular}{c|}
+ \\
\\
+ \\
+ \\
+ \\
+ \\
$?$ \\
$?$ \\
$\stackrel{?}{5}$ \\
$40 / 0^{\star}$
\end{tabular} & $\begin{array}{l}+ \\
+ \\
+ \\
+ \\
+ \\
+ \\
\mathbf{N} \\
\mathbf{N} \\
?\end{array}$ & $\mid \begin{array}{c}+ \\
+ \\
+ \\
+ \\
+ \\
+ \\
\mathbf{N} \\
\text { Rev } \\
\mathbf{L B B B} \\
\mathbf{3 0}\end{array}$ & $\begin{array}{l}+ \\
+ \\
+ \\
+ \\
+ \\
+ \\
+ \\
? \\
? \\
\mathbf{N} \\
60\end{array}$ & $\begin{array}{c}+ \\
+ \\
+ \\
\\
? \\
\mathrm{RV}^{?}+\end{array}$ & $\begin{array}{r}13 \\
6 \\
8 \\
13 \\
5 \\
6 \\
= \\
= \\
=\end{array}$ \\
\hline
\end{tabular}

^ Right ventricular pressure. Main pulmonary artery not entered.

found to be high in both. In the other 5 patients a peak systolic gradient of 10 to $60 \mathrm{~mm}$. $\mathrm{Hg}$ was recorded across the site of obstruction.

\section{CAuses of Acquired Pulmonary Stenosis}

Previously reported causes of acquired pulmonary stenosis, and the aetiology in our 13 cases, are summarized in Table I.

Malignant Reticuloses. In Case 1 the angiocardiogram indicated invasion of the right ventricle and compression of the pulmonary arteries by Hodgkin's disease of the thymus gland. Three previous cases of Hodgkin's disease in which there was acquired pulmonary stenosis have been published (Winter, 1958; Shaver, Bailey, and Marrangoni, 1965; Gough, Gold, and Gibson, 1967). Babcock et al. in 1962 described a patient with acquired pulmonary stenosis due to a lymphocytic lymphoma.

Teratoma. A benign teratoma caused pulmonary stenosis in 4 patients (Cases 2-5); in 3 of them no cardiac murmur had been heard at earlier examinations. Six cases of pulmonary stenosis due to a mediastinal teratoma or dermoid cyst have been previously reported (Rusby, 1944; Maier, 1948; Fry, Klein, and Barton, 1955; Eerland, 1962; Holstein et al., 1964; Gough et al., 1967).

Thymoma. In Case 6 a benign thymoma appeared on serial chest radiographs in a patient with pulmonary tuberculosis, and subsequent examination showed signs of pulmonary stenosis.

Tumours of Unknown Type. A mediastinal mass of unknown type produced almost complete occlusion of the right pulmonary artery and some compression of the main pulmonary artery in Case 7. Abrahams and Wood (1951) described a similar case due to a mediastinal tumour or cyst of undetermined type.

Pericardial Sarcoma. Case 8 illustrates a pleomorphic sarcoma of the pericardium invading the cavity of the right ventricle and the pulmonary artery, Tumours of the pericardium rarely cause impairment of cardiac function, and when this occurs the usual clinical picture is of cardiac tamponade which is either due to compression of the heart by the tumour or to a pericardial effusion. Waldenhausen, Lombardo, and Morrow in 1959 reported the only other case of pulmonary stenosis due to a pericardial tumour which we have been able to find. This was a pericardial mesothelioma, demonstrated at angiocardiography and confirmed at operation.

Bronchial Carcinoma. In 2 of our patients the pulmonary stenosis was due to a carcinoma. In Case 9, a primary anaplastic carcinoma of the left main bronchus had almost completely occluded the left pulmonary artery, and had invaded the main pulmonary artery. In Case 10 there was extensive infiltration of the mediastinum by a secondary 
adenocarcinoma. The tumour surrounded the origin of the great vessels and also compressed the right pulmonary artery and the superior vena cava. The site of the primary tumour was not identified but it seems likely to have been a bronchial carcinoma. Invasion of the right or left pulmonary artery by bronchial carcinoma is not uncommon, as shown by the angiographic studies of Neuhof, Sussman, and Nabatoff (1949) and Slesser, Britt, and Freer (1954). However, the clinical signs of pulmonary stenosis secondary to neoplasm of the lung have rarely been reported. Two such cases, both primary chondrosarcoma of the lung, have been described, one by Greenspan (1933) and the other by Lowell and Tuhy (1949).

Aneurysms of Ascending Aorta. Case 11 is an example of acquired pulmonary stenosis due to a large aneurysm of the ascending aorta, which was confirmed at thoracotomy. The pressure in the right ventricle and main pulmonary artery was $45 / 0$ $\mathrm{mm} . \mathrm{Hg}$, and there was a systolic gradient of $30 \mathrm{~mm}$. $\mathrm{Hg}$ between the right branch and the main pulmonary artery. The left pulmonary veins and superior vena cava were also compressed.

Watanabe et al. reported a case of pulmonary stenosis due to an aneurysm of the ascending aorta in 1967, and stated that "only 11 cases including our own have been reported since the first case report by Crawford and deVeer in 1932". But, on reviewing the literature, particularly the journals of pathology of the 19th century, we find that aortic aneurysms have been the commonest cause of acquired pulmonary stenosis. However, the incidence of cardiovascular syphilis, and therefore the incidence of aneurysms of the thoracic aorta, is now much lower than it was. The great majority of these aneurysms were syphilitic and had produced inflammatory lesions in adjacent structures. In many cases there was increasing encroachment of the aneurysmal sac into the lumen of the superior vena cava, cardiac chambers, the pulmonary artery and its branches, or into other structures such as the trachea or bronchi. Not infrequently the aneurysm had ruptured into the structure to which it had become adherent.

We have found reports of 83 cases in which an aortic aneurysm had ruptured either into the pulmonary artery or into the outflow tract of the right ventricle. Acquired pulmonary stenosis was recorded in $\mathbf{4 0}$ of these cases and was almost certainly present in another 4 . In the remaining 43 cases, the presence or absence of stenosis is not mentioned, but it seems probable that stenosis was present before rupture of the aneurysm in many of these patients, and this was referred to by Porter in 1942.
In addition, we have found reports of $49 \star$ cases of aneurysms of the aorta which had not ruptured, but which had produced pulmonary stenosis.

The following references to aortic aneurysms and acquired pulmonary stenosis are of some historical interest: Payen and Zeink, 1809; Wells, 1812; Henderson, 1836, 1843; Laennec, 1837; Hope, 1839; Thurnam, 1840; Wade, 1861; Peacock, 1868; and Gairdner, 1897, 1899.

Perforations of aortic aneurysms into the pulmonary artery have been reviewed in an excellent paper by Nicholson in 1943.

Constriction by Band. Case 12 was a patient who underwent 2 operations for removal of a calcified constricting pericardium and was included in the series reported by Portal et al. in 1966. Signs of pulmonary stenosis were noted in this patient 6 years after the second operation, and a systolic pressure gradient of $60 \mathrm{~mm}$. $\mathrm{Hg}$ across the right ventricular outflow tract was present. At a third thoracotomy the right ventricular infundibulum was bound down by fibrous tissue containing a calcified plaque. The constricting band was freed with difficulty.

Obstruction of the right ventricular outflow tract by a pericardial band after incomplete resection for constrictive pericarditis was first noted by Mounsey (1959). Since then, single cases have been reported by McGaff et al. (1963), Holstein et al. (1964), and Barros and Gómez (1967). Six cases of rheumatic pericarditis were described by Gouley in 1937 in which there were clinical signs of pulmonary stenosis. Necropsy in 5 revealed stenosis of the main pulmonary artery by grossly thickened pericardium. Weglicki et al. (1965) have described right ventricular outflow tract obstruction by a congenital pericardial band which caused pulmonary stenosis in a 15-year-old youth.

Pulmonary Stenosis due to Primary Tumour of Pulmonary Artery, PUlmonary Valve and Right Ventricular OUtflow Tract

Primary tumours of the heart are uncommon and are found in only $0.0017-0.05$ per cent of routine necropsies (Lymburner, 1934; Straus and Merliss, 1945). Approximately 25 per cent of all primary cardiac tumours are sarcomas.

Case 13 was a woman of 69 years in whom the signs of pulmonary stenosis and congestive cardiac failure had developed in the seventh decade: at necropsy a pleomorphic sarcoma of the pulmonary valve was found.

* References to these cases can be obtained by application to Dr. N. Pattinson, The Middlesex Hospital, London W.1. 
Primary sarcomas arising in the region of the right ventricular outflow tract or pulmonary valve, and causing the clinical haemodynamic or angiocardiographic features of pulmonary stenosis, have been reported by Mandelstamm (1923), Eschbach (1928), Froboese (1928), Nath (1931), Kudlich and Schuh (1934), Goedel (1935), Martin, Tuohy, and Will (1939), Haythorn, Ray, and Wolff (1941), Durgin and Ingleby (1946), Moegen (1951), Mannix and Lukash (1958), Wolf, Dickenman, and Langston (1960), Hagström (1961), Hallermann et al. (1963), Pund et al. (1963), Zamfir et al. (1964), Green, Crevasse, and Shanklin (1964), Munk, Griffel, and Kogan (1965), Goldstein and Mahoney (1966), and Sterns et al. (1966).

Myxomas of the pulmonary valve causing obstruction to right ventricular ejection have been reported by Blödorn (1955), Kishimoto and Sakaibori (1959), Catton, Guntheroth, and Reichenbach (1963), and Gottsegen et al. (1963).

Honey and Axelrad (1962) reported a case of intracardiac endodermal heterotopia in which there were clinical and haemodynamic features of right ventricular outflow tract obstruction.

\section{CASE Reports}

Case 1. A woman, aged 27, developed left chest pain, cough, and fever. The abnormal physical signs included pulsation in the left parasternal region and a harsh ejection systolic murmur at the same site. The electrocardiogram confirmed right ventricular hypertrophy, and the chest radiograph showed a large anterior mediastinal opacity in the region of the pulmonary artery. Angiocardiography demonstrated downward displacement of the right ventricle with invasion of the outflow tract and compression of the main pulmonary artery and its right and left branches (Fig. 1). The diagnosis of Hodgkin's disease was confirmed by biopsy of a left supraclavicular gland which appeared one month later.

After radiotherapy, signs of right ventricular outflow obstruction subsided and she remained fairly well for the next 10 years, though requiring six further courses of radiotherapy to the mediastinum, axillae, and upper part of the abdomen. In 1964 she became dyspnoeic and was found to have a high jugular venous pressure, a large left pleural effusion, ascites, and peripheral oedema. Cardiac catheterization and angiocardiography confirmed the clinical diagnosis of post-irradiation constrictive pericarditis without significant obstruction to right ventricular outflow. Pericardectomy was carried out, but the patient died. Necropsy showed increased interstitial fibrosis of the myocardium but no obvious abnormality of the myocardial muscle fibres and no obstruction to the right ventricular outflow tract or pulmonary arteries. There was no evidence of Hodgkin's disease.
Case 2. A woman of 35 developed central chest pain; at this time physical findings were normal. Ten months later a harsh pulmonary systolic murmur was first noted, and there was a slight increase in pulsation over the pulmonary artery. The electrocardiogram was normal, but the chest radiograph and angiocardiogram showed an anterior mediastinal mass containing some calcium

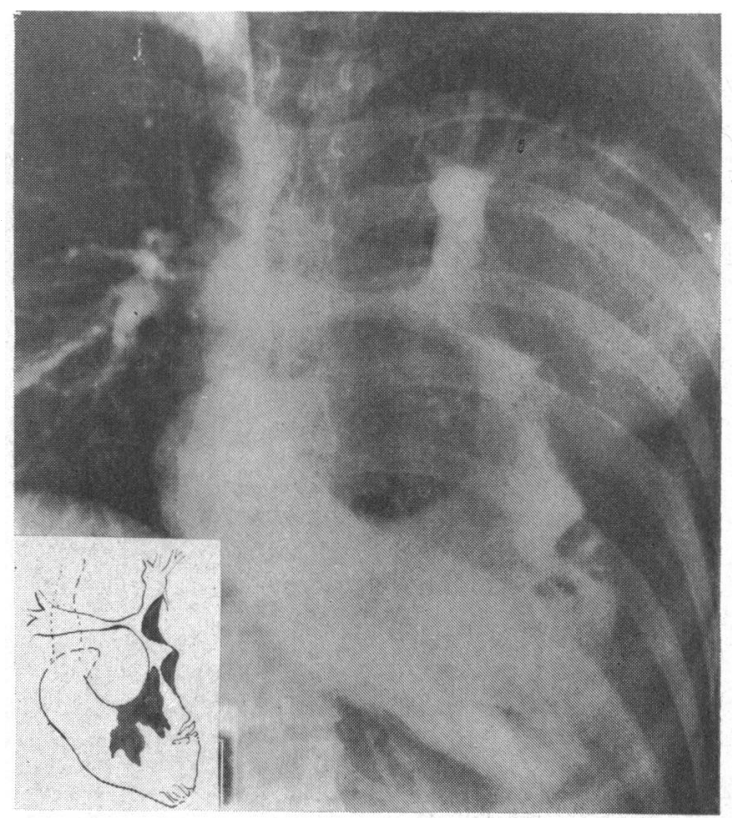

FrG. 1.-Case 1. Angiocardiogram shows invasion and/or compression of the outflow tract of the right ventricle, main pulmonary artery, and its right and left branches by Hodgkin's disease.

which compressed the main pulmonary artery (Fig. 2). At thoracotomy a benign cystic teratoma, which was adherent to the anterior chest wall and the pericardium, was successfully removed.

Case 3. A woman of 46 developed pain in the left chest, which was intensified by deep breathing. A diagnosis of pericarditis with effusion and pleurisy was made. The pericardium was tapped twice and she was treated with streptomycin in hospital for 7 months. She developed a slightly productive cough and noticed a little blood in the sputum on several occasions. Three years later she again developed pleuritic pain, slight effort dyspnoea, and orthopnoea. On auscultation there was a loud systolic murmur, and a softer immediate diastolic murmur, maximal at the second left intercostal space. There were no other abnormal physical signs. The chest radiograph showed an opacity in the left hilum, and angiocardiography confirmed a mediastinal tumour compressing the main pulmonary artery. At thoracotomy the pulmonary artery was found to be com- 


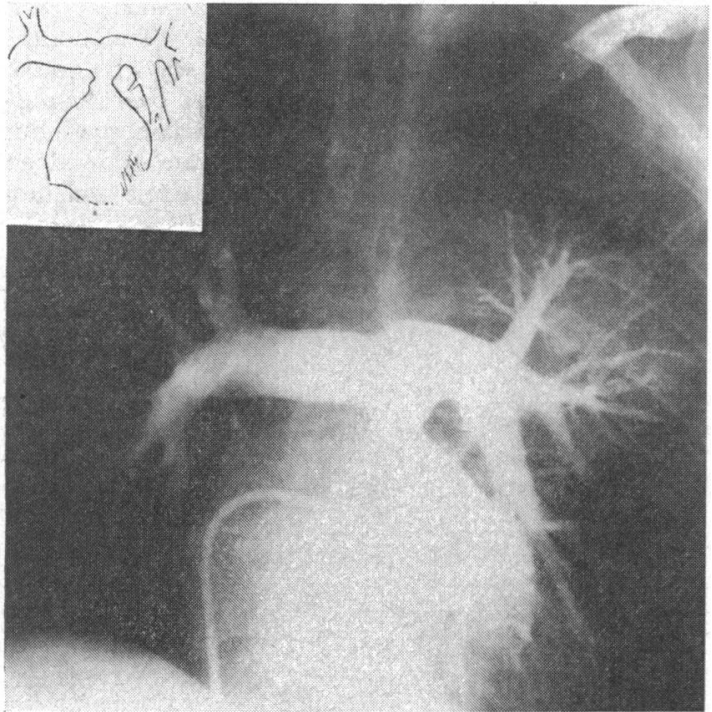

FIG. 2.-Case 2. Angiocardiogram shows narrowing of the transverse diameter of the main pulmonary artery by a benign teratoma.

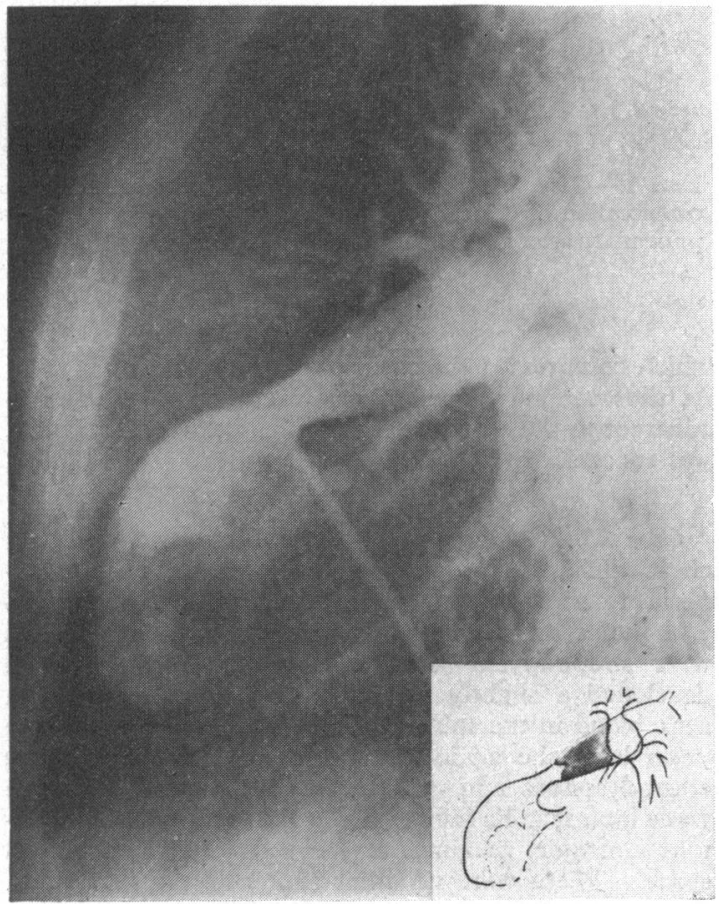

FIG. 3.-Case 4. Angiocardiogram shows compression and postero-inferior displacement of the outflow tract of the right ventricle and narrowing of the transverse diameter of the main pulmonary artery by a dermoid cyst. pressed by a large mediastinal mass which invaded the left lung. The tumour was successfully removed and histologically was a cystic teratoma.

Case 4. A girl of 18 was first seen with a one-year history of chest pain and dyspnoea. The only abnormal physical findings were increased pulsation in the left parasternal region and a loud pulmonary ejection murmur. The electrocardiogram was normal, but the chest radiograph showed a large heart shadow, with a bulge in the region of the main pulmonary artery. Cardiac catheterization showed a right ventricular pressure of $50 / 0 \mathrm{~mm}$. $\mathrm{Hg}$, but the pulmonary artery could not be entered. The right ventricular angiocardiogram subsequently showed backward displacement and compression of the right ventricular outflow tract, proximal to the main pulmonary artery (Fig. 3). At thoracotomy a benign dermoid cyst was removed and a pericardial effusion was evacuated.

Case 5. A young woman of 21 was found to have a loud systolic ejection murmur at the left sternal edge. She was asymptomatic and had been passed as normal at a previous examination in 1957. The electrocardiogram was normal, but the chest radiograph showed an anterior mediastinal mass. At cardiac catheterization there was a $35 \mathrm{~mm}$. $\mathbf{H g}$ systolic gradient between the main pulmonary artery and right ventricle. A right ventricular angiocardiogram showed an antero-mediastinal mass compressing the main pulmonary artery. At thoracotomy a tumour, $10 \times 5 \times 7 \mathrm{~cm}$., was removed, which histologically was a benign cystic teratoma.

Case 6. A man of 39 had been previously treated for left apical pulmonary tuberculosis. In 1964 he felt well but a routine chest radiograph showed a mass in the region of the pulmonary artery. The only physical abnormality was a moderately loud systolic murmur, maximal at the second left intercostal space. The electrocardiogram was normal. At cardiac catheterization the right ventricular pressure was $35 / 0 \mathrm{~mm}$. $\mathrm{Hg}$, and the main pulmonary artery pressure was $25 / 10 \mathrm{~mm}$. $\mathrm{Hg}$. A right ventricular angiocardiogram demonstrated compression of the pulmonary artery by the anterior mediastinal mass (Fig. 4). At thoracotomy a lobulated encapsulated tumour, $10 \times 10 \times 3 \mathrm{~cm}$., was removed. Histologically this was a benign thymoma.

Case 7. A man aged 34 was referred with a diagnosis of syphilitic aortic incompetence. He had complained of exertional dyspnoea and chest pain for two years. The abnormal findings on examination included increased venous pressure, a collapsing pulse, blood pressure $190 / 100 \mathrm{~mm}$. $\mathrm{Hg}$, moderate cardiac enlargement, an aortic diastolic murmur, and an ejection murmur maximal at the second left interspace. The chest radiograph showed slight widening of the superior mediastinum, and in the lateral view there was a mediastinal mass below the aortic arch. An aortogram confirmed the presence of aortic incompetence. A right ventricular angiocardiogram showed complete occlusion of the right pulmonary artery by the mediastinal mass and com- 
pression of the right side of the main pulmonary artery (Fig. 5). The superior vena cava was also shown to be compressed. The patient declined further investigation or treatment.

Case 8. A man of 57 was admitted to hospital in 1963 with a history of progressive dyspnoea for six months. He had had two attacks of right-sided pleuritic pain, the first a month before, the second 10 days before admission, which were associated with haemoptysis and fever. The physical findings included increased jugular venous pressure, sinus rhythm, blood pressure 155/100 $\mathrm{mm}$. $\mathrm{Hg}$, a diffuse pulsation in the left parasternal region, and a loud systolic ejection murmur at the left sternal edge. Over the right lower lobe there was a pleural friction rub and diminished air entry. The chest radiograph showed an opacity in the right lower zone, thought to be due to pulmonary infarction. The electrocardiogram was normal. Subsequent radiographs demonstrated a mass in the anterior mediastinum. At cardiac catheterization the right ventricular pressure was $68 / 0$ $\mathrm{mm}$. $\mathrm{Hg}$, and the main pulmonary artery pressure $48 / 18$ $\mathrm{mm}$. Hg. Angiocardiography showed an anterior mediastinal mass invading the right ventricular outflow tract, displacing it and both pulmonary arteries backwards. There was also invasion of the right side of the main pulmonary artery which extended to the origin of the right pulmonary artery, and a well-defined mass was present within the lumen of the right pulmonary artery (Fig. 6). He improved for a time after radiotherapy, but died in May 1965. Necropsy showed a large mediastinal mass which appeared to arise from the anterior pericardium and did not spread beyond the parietal pericardium. The pulmonary artery and right ventricle were compressed by the tumour. The histology was that of a pleomorphic sarcoma.

Case 9. A man of 60 was first seen with a six-week history of dull retrosternal pain radiating to the left shoulder. The abnormal physical findings were a blood pressure of $200 / 90 \mathrm{~mm}$. $\mathrm{Hg}$, a faint systolic thrill, palpable over the upper part of the sternum, and a loud systolic and diastolic murmur maximal at the left sternal edge. The electrocardiogram was normal, but the chest radiograph showed masses at both hila. At cardiac catheterization the right ventricular pressure was $40 / 0 \mathrm{~mm}$. $\mathrm{Hg}$, and a right ventricular angiocardiogram outlined an irregular filling defect in the lumen of the main pulmonary artery. The left pulmonary artery was almost completely occluded $2 \mathrm{~cm}$. beyond its origin. A left thoracotomy showed a large mass arising from the hilum invading the main pulmonary artery, the left branch, and the chest wall. Biopsy confirmed anaplastic bronchial carcinoma.

Case 10. A woman of $\mathbf{4 3}$ was first seen with a history of retrosternal pain. Clinical examination, chest radiograph, electrocardiogram, and barium meal were all normal. Two years later she was again seen with the additional symptoms of exertional dyspnoea and palpitation. At this time the veins in the left side of the neck were distended but not pulsatile. On the right side the

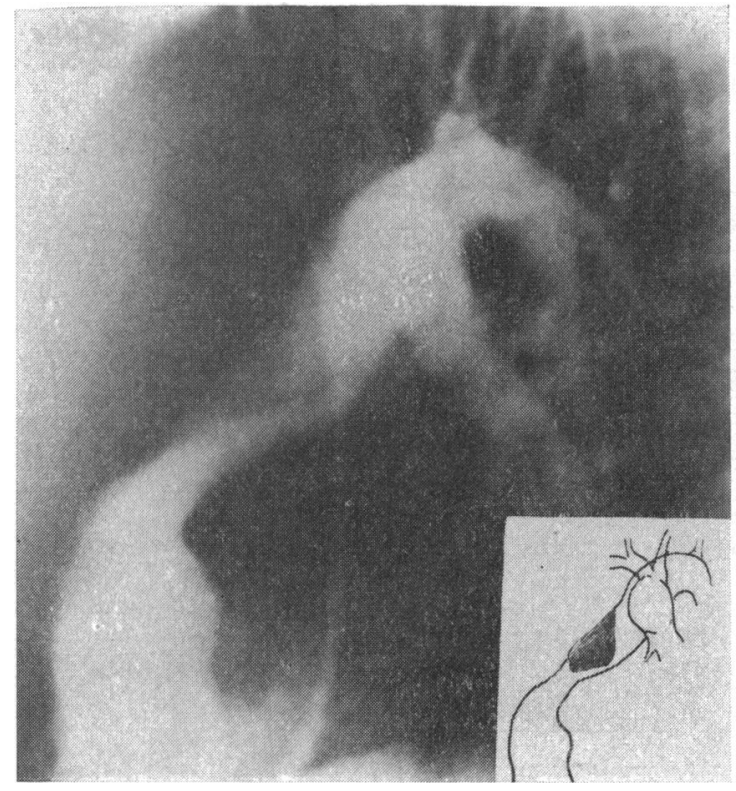

Fig. 4.-Case 6. Angiocardiogram shows compression on the anterior wall of the main pulmonary artery by a benign thymoma.

jugular venous pulse was normal, but the pressure was raised some $2 \mathrm{~cm}$. above the sternal angle. The blood pressure was $170 / 95 \mathrm{~mm}$. $\mathrm{Hg}$. Clinically the heart was enlarged with basal systolic and diastolic murmurs, neither of which were conducted into the neck. The

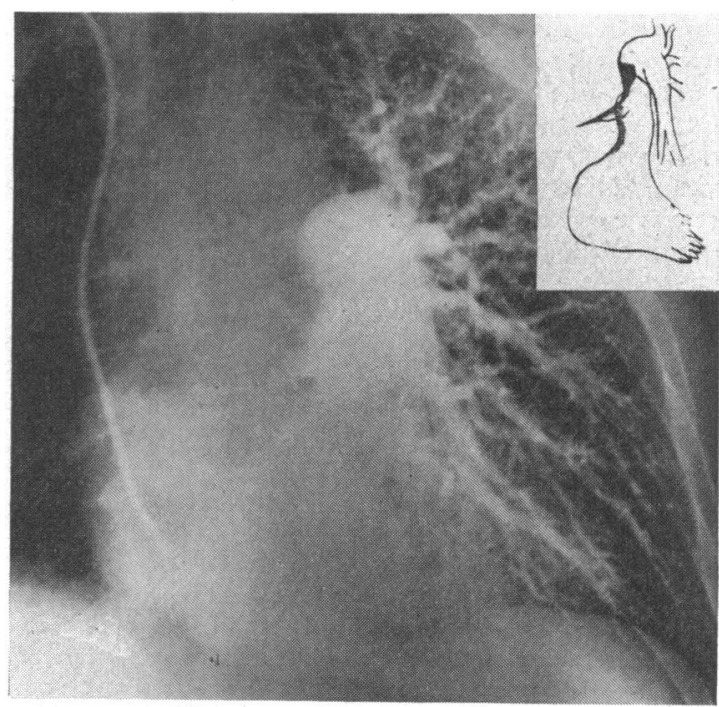

Fig. 5.-Case 7. Angiocardiogram shows complete occlusion of the right pulmonary artery and compression, with displacement to the left of the main pulmonary artery by a mediastinal mass of unknown aetiology. 


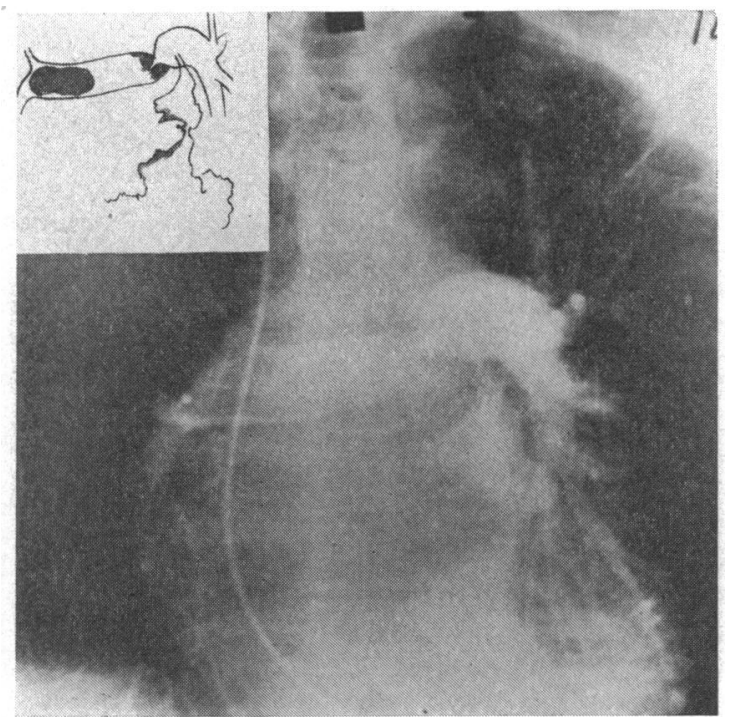

Fig. 6.-Case 8. Angiocardiogram shows invasion and compression of the outflow tract of the right ventricle, main pulmonary artery, and the origin of the right pulmonary artery by a pericardial sarcoma. A large oval mass lies within the lumen of the right pulmonary artery.

electrocardiogram was normal, except for a low voltage. The chest radiograph confirmed generalized cardiac enlargement. Cardiac catheterization was attempted, but the catheter could not be passed beyond the lower end of the superior vena cava. At thoracotomy in December 1957 the base of the heart and great vessels were surrounded by an irregular woody mass which extended forward to the sternum and backwards to the trachea which it appeared to infiltrate. The superior vena cava ran through the mass and a marked thrill was felt at the root of the right lung, probably due to stenosis of the right pulmonary artery. Biopsy showed an infiltrating adenocarcinoma, with a strong fibrous reaction around it. It was considered to be a secondary carcinoma but the source of the primary was not evident. She was treated with radiotherapy and died 4 years after first being seen. A necropsy was not obtained.

Case 11. A woman of 57 developed chest pain from a pleuro-pericarditis. Radiographs showed an enlarged heart shadow and a left pleural effusion. Both the pleural and pericardial effusions resolved spontaneously, and the radiographic appearance returned to normal. She remained well until 4 years later when she developed exertional dyspnoea; this was progressive and she was admitted to hospital 3 months later. There was no loss of weight, cough, haemoptysis, or dysphagia. The abnormal physical signs included sternal depression, an $8 \mathrm{~cm}$. increase in the jugular venous pressure, with poor pulsation, the trachea deviated to the left, an abnormal pulsation in the left parasternal region over which there was a loud systolic ejection murmur, immediate diastolic murmur, and reversed splitting of the second heart

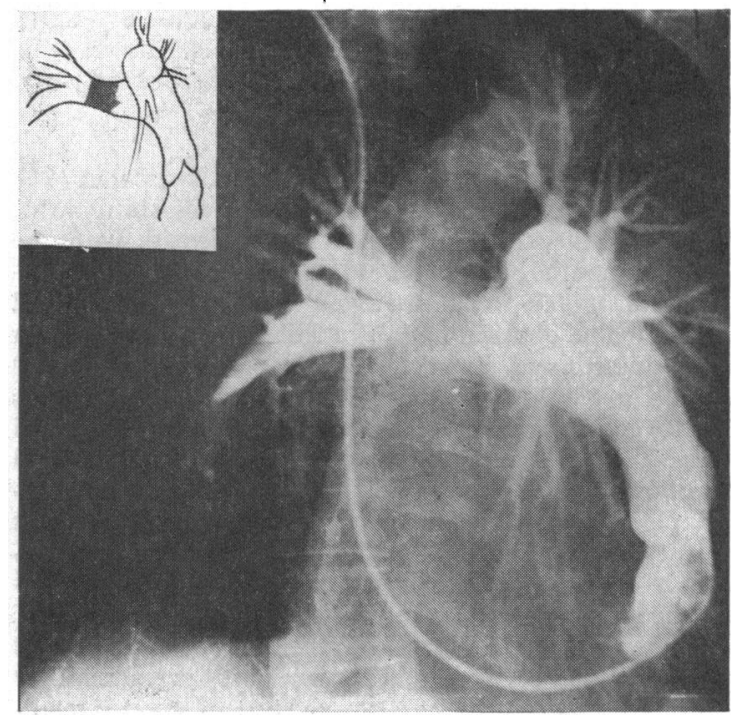

Fig. 7.-Case 11. Angiocardiogram shows displacement of the right ventricle and pulmonary artery to the left and prominent antero-posterior compression of the right pulmonary artery by a huge aneurysm of the ascending aorta.

sound. To the right of the sternum there was a continuous murmur, and over the left lower chest posteriorly air entry was diminished. The electrocardiogram showed a left bundle-branch block and the radiographs revealed displacement and rotation of the heart to the left by a large mediastinal mass. There was some collapse of the left lower lobe. Reviewing previous radiographs, the anterior mediastinal mass first appeared in 1962. Cardiac catheterization showed a $30 \mathrm{~mm}$. Hg systolic gradient between the main pulmonary artery $(45 / 13 \mathrm{~mm} . \mathrm{Hg})$ and both the upper and lower branches of the right pulmonary artery $(15 / 7 \mathrm{~mm} . \mathrm{Hg})$. There was no pressure gradient between the main pulmonary artery and the left branch. The right ventricular pressure was $45 / 0 \mathrm{~mm}$. $\mathrm{Hg}$ and there was an $8 \mathrm{~mm}$. $\mathrm{Hg}$ gradient between the right atrium and superior vena cava. A right ventricular angiocardiogram showed displacement of the right ventricle and outflow tract backwards and to the left. The main pulmonary artery was displaced posteriorly. There was narrowing of the antero-posterior diameter of the right pulmonary artery, just proximal to the origin of the right upper lobe branch (Fig. 7). The left pulmonary veins were grossly narrowed just before they entered the left atrium. An injection of contrast medium into the superior vena cava showed narrowing at its lower end. Thoracotomy revealed a large aneurysm of the ascending aorta.

Case 12. A man of 36 was first seen with calcific constrictive pericarditis. At operation the pericardium was stripped from most of the left ventricle and from the anterior surface of the right ventricle. Histologically there was no evidence of active tuberculosis, but a course 


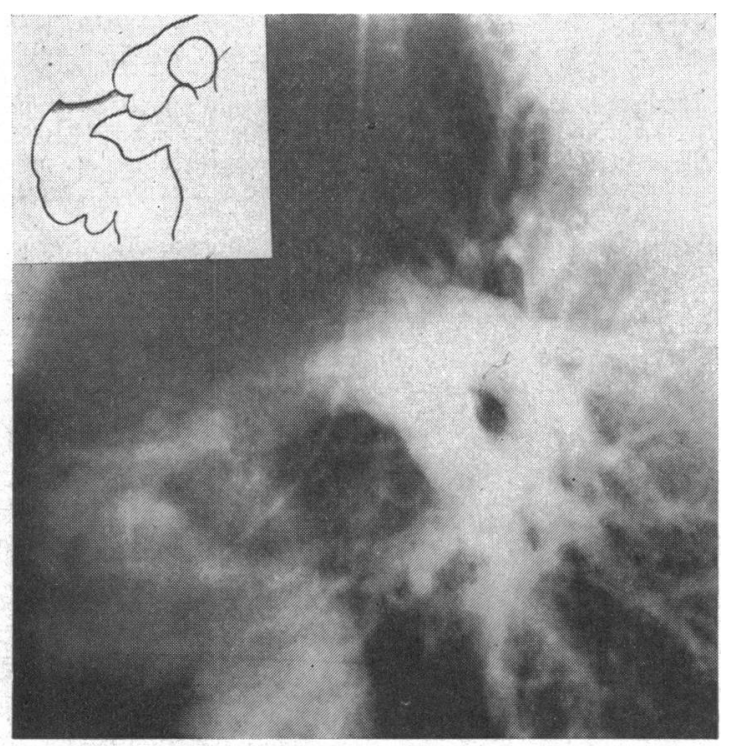

FIG. 8.-Case 12. Angiocardiogram shows constriction of the outflow tract of the right ventricle by a band of thick pericardium.

of streptomycin and isoniazid was given. Following operation he improved clinically but the jugular venous pressure remained raised. At a second thoracotomy 4 years later the ventricles appeared fibrosed, but there was no constriction. There was, however, a calcified sheet covering the right atrium which appeared to constrict the junction of the superior vena cava and right atrium. This was removed, but the ventricles were untouched. There was little improvement following the second operation and 10 years after first presenting he again had ascites, and an increase in the jugular venous pressure above the angle of the jaw. He remained in sinus rhythm with a blood pressure of $115 / 60 \mathrm{~mm}$. $\mathrm{Hg}$. At the left sternal edge there was a loud systolic ejection murmur and at the apex a short delayed diastolic murmur. The liver and spleen were both enlarged, but there was no peripheral oedema. The chest radiograph showed considerable pericardial calcification in the region of the right ventricular outflow tract. The electrocardiogram was normal. Cardiac catheterization demonstrated a systolic gradient of $60 \mathrm{~mm}$. $\mathrm{Hg}$ between the main pulmonary artery and right ventricle. The angiocardiogram showed a small right ventricle, with narrowing of the right ventricular outflow tract for $3 \mathrm{~cm}$. below the pulmonary valve (Fig. 8). A year later a third thoracotomy was carried out. The outflow tract to the right ventricle was bound down by fibrous tissue which contained a plaque of calcium $1 \mathrm{~cm}$. wide. In systole the right ventricle bulged freely, proximal to the constriction. The right ventricular outflow tract was freed with difficulty, and two months after operation the jugular venous pressure was $5 \mathrm{~cm}$. above the sternal angle. The systolic ejection murmur had disappeared and the liver was no longer palpable. He was free from ascites and peripheral oedema, but the spleen remained enlarged.

Case 13. A woman of 69 had had a left radical mastectomy for carcinoma of the breast in 1953. Eleven years later she noticed progressive swelling of the ankles and in February the following year exertional dyspnoea. When seen in April she had a sinus tachycardia and a jugular venous pressure raised $6 \mathrm{~cm}$. above the sternal angle, with a dominant "a" wave. There was a moderately loud systolic murmur at the left sternal edge and the chest radiograph showed slight cardiac enlargement which was not evident clinically. The electrocardiogram showed a $\mathrm{P}$ pulmonale and moderate right ventricular hypertrophy. She improved temporarily with routine medical therapy, but by December 1965 was admitted to hospital in gross cardiac failure, from which she died. Necropsy showed a firm tumour which arose from the pulmonary valve cusps and extended into the main pulmonary artery. Histologically this was a pleomorphic sarcoma.

\section{Discussion}

In our experience, acquired pulmonary stenosis is not so rare as previously supposed (Gough et al., 1967). We have only included cases where there has been clinical or haemodynamic evidence of obstruction to the right ventricular outflow.

Chest pain, dyspnoea, and a loud pulmonary systolic murmur were present in 6 of our 13 cases. This triad was considered to be the best diagnostic guide, particularly if the patient was known to be free from cardiac murmurs at a previous medical examination.

The commonest cause of acquired pulmonary stenosis has been aneurysm of the aorta. We have found reports of 89 such cases: 40 of them had ruptured into the pulmonary artery or outflow tract of the right ventricle, while 49 of them had remained intact. Many additional cases of ruptured aneurysm have been reported in which the presence or absence of pulmonary stenosis was not mentioned, but it seems likely that stenosis was in fact present in a number of these.

The majority of these cases of aneurysm were reported in journals of pathology at a time when cardiovascular syphilis was commoner than it is today. It seems from our own cases that tumours of the anterior mediastinum are now the commonest cause.

\section{SUMMARY}

The clinical, haemodynamic, and angiographic findings in 13 patients suffering from acquired pulmonary stenosis are described. Obstruction of the main pulmonary artery or the outflow tract of the right ventricle was due to an anterior mediastinal tumour in 6 cases. In the remainder the obstruc- 
tion was caused by one of the following: pericardial sarcoma, bronchial carcinoma, secondary carcinoma, aneurysm of the ascending aorta, constrictive pericarditis, or a mediastinal mass of unknown histology.

We are indebted to our colleagues at the Middlesex Hospital for permission to publish the clinical findings in their patients, and to Mr. G. C. W. James who referred Case 8 to us for investigation. We are most grateful to Dr. C. M. Oakley for allowing us to include Cases 5, 7, and 10 investigated at the Hammersmith Hospital and to Mr. W. P. Cleland for Case 3 investigated at King's College Hospital.

\section{REFERENCES}

Abrahams, D. G., and Wood, P. (1951). Pulmonary stenosis with normal aortic root. Brit. Heart f., 13, 519.

Babcock, K. B., Judge, R. D., and Bookstein, J. J. (1962). Acquired pulmonic stenosis. Report of a case caused by mediastinal neoplasm. Circulation, 26, 931.

Barros, J. L., and Gómez, F. P. (1967). Pulmonary stenosis due to external compression by a pericardial band. Brit. Heart f., 29, 947.

Blödorn, M. (1955). Myxom der Pulmonalklappe bzw. der Art. pulmonalis. Zbl. allg. Path. path. Anat., 94, 283.

Catton, R. W., Guntheroth, W. G., and Reichenbach, D. D. (1963). A myxoma of the pulmonary valve causing severe stenosis in infancy. Amer. Heart f., 66, 248.

Crawford, J. H., and deVeer, J. A. (1932). Aneurysm of the aorta producing pulmonary stenosis and bundle-branch block. Amer. Heart F., 7, 780.

Durgin, B., and Ingleby, H. (1946). Primary sarcoma of the pulmonary artery. Clinics, 5, 182.

Eerland, L. D. (1962). Some special cases of pulmonary stenosis. Ned. T. Geneesk., 106, 332.

Eschbach, H. (1928). Utber ein malignes Leiomyom des Endocards mit Verstopfung der Lungenschlagader. Beitr. path. Anat. allg. Path., 80, 672.

Froboese, C. (1928). Emboliformes Sarkom des Hauptstammes der Pulmonalarterie. Zbl. allg. Path. path. Anat., 44, 148.

Fry, W., Klein, C. L., and Barton, H. C. (1955). Malignant mediastinal teratoma simulating cardiovascular disease. Dis. Chest, 27, 537.

Gairdner, W. T. (1897). Specimens illustrating aneurysms of the arch of the aorta which either opened into or pressed upon the vena cava superior or the pulmonary artery. Glasg. med. F., 48, 120.

- (1899). Case of a small aneurysm of the first part of the arch of the aorta, opening into the pulmonary artery and conus arteriosus of the right ventricle. Glasg. Hosp. Rep., $2,1$.

Goedel, A. (1935). Zur Kenntnis des primären Lungenschlagadersarkoms. Frankfurt. Z. Path., 49, 1.

Goldstein, S., and Mahoney, E. B. (1966). Right ventricular fibrosarcoma causing pulmonic stenosis. Amer. $\mathcal{F}$. Cardiol., 17, 570.

Gottsegen, G., Wessely, J., Árvay, A., and Temesvári, A. (1963). Right ventricular myxoma simulating pulmonic stenosis. Circulation, 27, 95.

Gough, J. H., Gold, R. G., and Gibson, R. V. (1967). Acquired pulmonary stenosis and pulmonary artery compression. Thorax, 22, 358.

Gouley, B. A. (1937). Constriction of the pulmonary artery by adhesive pericarditis. Amer. Heart f., 13, 470.
Green, J. R., Crevasse, L. E., and Shanklin, D. R. (1964). Fibromyxosarcoma of the pulmonary artery. Amer. f. Cardiol., 13, 547.

Greenspan, E. B. (1933). Primary osteoid chondrosarcoma of the lung: report of a case. Amer. F. Cancer, 18, 603.

Hagström, L. (1961). Malignant mesenchymoma in pulmonary artery and right ventricle. Acta path. microbiol. scand., 51, 87.

Hallermann, F. J., Kincaid, O. W., Brown, A. L., and Daugherty, G. W. (1963). Rhabdomyosarcoma of the heart producing right ventricular outflow obstruction. F. Amer. med. Ass., 184, 939.

Haythorn, S. R., Ray, W. B., and Wolff, R. A. (1941). Primary fibromyxosarcomas of the heart and pulmonary artery. Amer. F. Path., 17, 261.

Henderson, W. (1836). On the sounds afforded by substernal aneurysms. Edinb. med. surg. F., 45, 311.

- (1843). Aneurism of the arch of the aorta. Lond. Edinb. Monthly \}. med. Sci., 3, 452.

Holstein, J., Kanehl, E., Richter, K., Geissler, W., and Porstmann, W. (1964). Funktionelle Pulmonalstenosen bei Pericarditis constrictiva und Mediastinaltumoren. Fortschr. Röntgenstr., 101, 272.

Honey, M., and Axelrad, M. A. (1962). Intracardiac endodermal heterotopia. Brit. Heart F., 24, 667.

Hope, J. (1839). A Treatise on the Diseases of the Heart and Great Vessels, 3rd ed., p. 466. John Churchill, London.

Kishimoto, M., and Sakaibori, S. (1959). Primary tumour of the heart: report of a case with myxofibroma of the right ventricle. Amer. Heart f., 57, 769.

Kudlich, H., and Schuh, W. (1934). Ein Beitrag zum myoplastischen Sarkom der Lungenschlagader. Virchows Arch. path. Anat., 294, 113.

Laennec, R. T. H. (1837). Traité de l'Auscultation Médiate et des Maladies des Poumon et du Coeur, 4th ed., p. 470. Bruxelles.

Lowell, L. M., and Tuhy, J. E. (1949). Primary chondrosarcoma of the lung. F. thorac. Surg., 18, 476.

Lymburner, R. M. (1934). Tumours of the heart: histopathological and clinical study. Canad. med. Ass. f., 30, 368.

McGaff, C. J., Haller, J. A., Leight, C., and Towery, B. T. (1963). Subvalvular pulmonary stenosis due to constriction of the right ventricular outflow tract by a pericardial band. Amer. F. Med., 34, 142.

Maier, H. C. (1948). Dermoid cysts and teratomas of the mediastinum with unusual features. Arch. Surg. (Chic.), 57, 154.

Mandelstamm, M. (1923). U'ber primäre Neubildungen des Herzens. Virchows Arch. path. Anat., 245, 43.

Mannix, E. P., and Lukash, L. (1958). Primary rhabdomyosarcoma of the heart producing marked obstruction of the pulmonary valve. Bull. St Francis Hosp. (Roslyn), $15,14$.

Martin, W. C., Tuohy, E. L., and Will, C. (1939). Primary tumor of the heart (entrance of the pulmonary artery). Case report. Amer. Heart F., 17, 728.

Moegen, P. (1951). Primäres Sarkom der Arterienintima. Verh. dtsch. Ges. Path., 35, 267.

Mounsey, P. (1959). Annular constrictive pericarditis with an account of a patient with functional pulmonary, mitral, and aortic stenosis. Brit. Heart f., 21, 325.

Munk, J., Griffel, B., and Kogan, J. (1965). Primary mesenchymoma of the pulmonary artery: radiological features. Brit. F. Radiol., 38, 104.

Nath, V. (1931). A case of primary sarcoma of the heart. Indian med. Gaz., 66, 673.

Neuhof, H., Sussman, M. L., and Nabatoff, R. A. (1949). Angiocardiography in the differential diagnosis of pulmonary neoplasms. Surgery, 25, 178. 
Nicholson, R. E. (1943). Syndrome of rupture of aortic aneurysm into the pulmonary artery. Ann. intern. Med., 18, 286.

Payen, and Zeink (1809). Une observation sur un anévrisme de l'aorte pénétrant dans l'artère pulmonaire. Bull. Fac. méd. Paris, 2, 32.

Peacock, T. B. (1868). Aneurysm of the ascending aorta pressing upon the base of the right ventricle and opening into the origin of the pulmonary artery. Trans. path. Soc. Lond., 19, 111.

Portal, R. W., Besterman, E. M. M., Chambers, R. J., Sellors, T. H., and Somerville, W. (1966). Prognosis after operation for constrictive pericarditis. Brit. med. $\mathcal{F}$., 1, 563.

Porter, W. B. (1942). The syndrome of rupture of an aortic aneurysm into the pulmonary artery. Amer. Heart f., 23, 468.

Pund, E. E., Collier, T. M., Cunningham, J. E., and Hayes, J. R. (1963). Primary cardiac rhabdomyosarcoma presenting as pulmonary stenosis. Amer. F. Cardiol., 12, 249.

Rusby, N. L. (1944). Dermoid cysts and teratomata of the mediastinum. A review. f. thorac. Surg., 13, 169.

Shaver, V. C., Bailey, W. R., and Marrangoni, A. G. (1965). Acquired pulmonic stenosis due to external cardiac compression. Amer. F. Cardiol., 16, 256.

Slesser, B. V., Britt, R. G., and Freer, J. L. (1954). Assessing the inoperability of bronchial carcinoma by angiocardiography. Thorax, 9, 91.

Sterns, L. P., Eliot, R. S., Varco, R. L., and Edwards, J. E. (1966). Intracavitary cardiac neoplasms. A review of fifteen cases. Brit. Heart f., 28, 75.

Straus, R., and Merliss, R. (1945). Primary tumor of the heart. Arch. Path., 39, 74.
Thurnam, J. (1840). On aneurisms and especially spontaneous varicose aneurisms of the ascending aorta and sinuses of Valsalva. Med-chir. Trans., 23, 323.

Wade, W. F. (1861). On a case of aortic aneurism, in which a communication with the pulmonary artery was recognised during life by means of physical diagnosis. Medchir. Trans., 44, 211.

Waldenhausen, J. A., Lombardo, C. R., and Morrow, A. G. (1959). Pulmonic stenosis due to compression of the pulmonary artery by an intrapericardial tumor. $\mathcal{f}$. thorac. Surg., 37, 679.

Watanabe, T., Miyazawa, K., Tsukamoto, M., and Shibota, Y. (1967). Syphilitic aneurysm of the ascending aorta producing pulmonic stenosis by compression. Amer. f. Cardiol., 20, 575.

Weglicki, W. B., Lee, J. F., Brown, I. W., and Whalen, R. E. (1965). Infundibular pulmonic stenosis due to a pericardial band. Amer. F. Cardiol., 16, 262.

Wells, W. C. (1812). A case of aneurysm of the aorta communicating with the pulmonary artery. Trans. Soc. Improv. med.-chir.Knowledge, 3, 85.

Winter, B. (1958). Pulmonic stenosis produced by compression of heart by anterior mediastinal tumor. Amer. Heart f., 55, 18.

Wolf, P. L. Dickenman, R. C., and Langston, J. D. (1960). Fibrosarcoma of the pulmonary artery, masquerading as a pheochromocytoma. Amer. F. clin. Path., 34, 146.

Zamfir, C., Efanov, A., Singer, D., and Sandu, G. (1964) Mediastino-pulmonary polymorphous sarcoma with pericardio-myocardial invasion and formation of a polypus stricture causing stenosis of the pulmonary artery. (In Roumanian.) Med.-intern., 16, 741. 